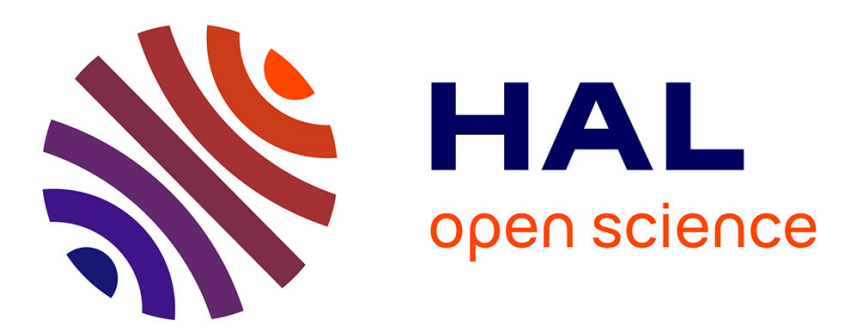

\title{
Brønsted Acid and H-Bond Activation in Boronic Acid Catalysis
}

Shaofei Zhang, David Lebœuf, Joseph Moran

\section{To cite this version:}

Shaofei Zhang, David Lebœuf, Joseph Moran. Brønsted Acid and H-Bond Activation in Boronic Acid Catalysis. Chemistry - A European Journal, 2020, 26 (44), pp.9883-9888. 10.1002/chem.202001902 . hal-02990292

\section{HAL Id: hal-02990292 \\ https://hal.science/hal-02990292}

Submitted on 30 Nov 2020

HAL is a multi-disciplinary open access archive for the deposit and dissemination of scientific research documents, whether they are published or not. The documents may come from teaching and research institutions in France or abroad, or from public or private research centers.
L'archive ouverte pluridisciplinaire HAL, est destinée au dépôt et à la diffusion de documents scientifiques de niveau recherche, publiés ou non, émanant des établissements d'enseignement et de recherche français ou étrangers, des laboratoires publics ou privés. 


\title{
Brønsted Acid and H-Bond Activation in Boronic Acid Catalysis
}

\author{
Shaofei Zhang, David Lebœuf and Joseph Moran* \\ S. Zhang, Dr. D. Lebœuf and Prof. Dr. J. Moran \\ University of Strasbourg, CNRS, ISIS UMR 7006 \\ 67000 Strasbourg, France \\ E-mail: moran@unistra.fr \\ Supporting information for this article is given via a link at the end of the document
}

\begin{abstract}
Boronic acid catalysis has emerged as a mild method for promoting a wide variety of reactions. It has been proposed that the mode of catalysis involves Lewis acid or covalent activation of hydroxyl groups by boron, but limited mechanistic evidence exists. Here, we reinvestigate representative boronic acid-catalyzed reactions of alcohols and oximes. We interpret a series of control experiments with boronic and Brønsted acids along with correlations between their reactivity and their acidity measured by the GutmannBeckett method. Overall, we conclude that the major modes of catalysis involve either dual $\mathrm{H}$-bond catalysis or Brønsted acid catalysis. We show that strong Brønsted acids are generated in situ from covalent assembly of the boronic acids with hexafluoroisopropanol, explaining why the solvent had such a major impact on the reactivity. This new insight should guide the future development of boronic acid catalysis, where the diverse and solventspecific nature of catalytic modes has been overlooked.
\end{abstract}

Boronic acids have emerged as a promising class of catalysts ${ }^{[1]}$ that enable dehydrative nucleophilic substitution or rearrangements of alcohols, ${ }^{[2]}$ Beckmann rearrangement of oximes, ${ }^{[3]}$ and various reactions involving either carboxylic acids ${ }^{[4]}$ or epoxides ${ }^{[5]}$ under mild conditions. In depth studies into the catalytic mechanism have been performed in the case of carboxylic acids, ${ }^{[4 \mathrm{c}, 4 \mathrm{~h}]}$ whereas only preliminary mechanistic evidence exists for the reactions of alcohols and oximes. ${ }^{[2 \mathrm{~d}, 2 \mathrm{j} ; 3 \mathrm{~b}]}$ The arylboronic acid catalyst systems required for reactions involving alcohols and oximes (B1-B3, Scheme 1) are substantially more electrophilic than those used for the activation of carboxylic acids, the former requiring either multiple electronwithdrawing groups, cationic boronic acids or complexation with highly electronically deactivated diols. Another critical parameter in these reactions is the solvent. Our group as well as many others have pointed out the enabling effect of solvents, such as hexafluoroisopropanol (HFIP) ${ }^{[6-7]}$ and nitromethane $\left(\mathrm{MeNO}_{2}\right),{ }^{[8]}$ on Brønsted and Lewis acid-catalyzed reactions through the formation of an $\mathrm{H}$-bond network. In the case of HFIP, we emphasized that the role of the catalysts was to significantly increase the acidity of an $\mathrm{H}$-bond cluster of HFIP, which was the true catalytically active species..$^{[7,7 \mathrm{~m}]}$ Our reflections on the reactivity of arylboronic acids started during our investigations on the $\mathrm{TfOH}$-catalyzed arylative ring-opening of unactivated cyclopropanes in HFIP (Table 1, entry 1.1). ${ }^{[7 \mathrm{~m}]}$ We were puzzled by the reactivity of two catalyst systems typically used for activation of alcohols and oximes (B1 and B3), as they were able to trigger the ring-opening of phenylcyclopropane to generate product 1 (entries 1.2 and 1.5). Given the absence of an $\mathrm{OH}$ functional group in the substrate and the lack of Frustrated Lewis a) Friedel-Crafts reaction of benzylic alcohols

(J. Am. Chem. Soc. 2015, 137, 9694-9703 - Ref [2g])

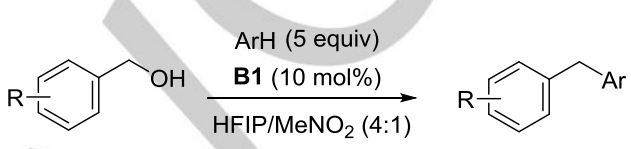

b) Beckmann rearrangement of oximes

(J. Am. Chem. Soc. 2018, 140, 5264-5271 - Ref [3b])

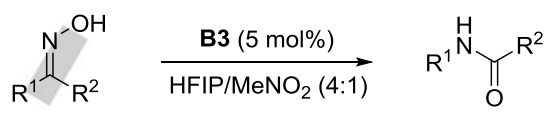

c) Carbo- and heterocyclization of allylic alcohols (Angew. Chem. Int. Ed. 2012, 51, 6187-6190 - Ref [2f])

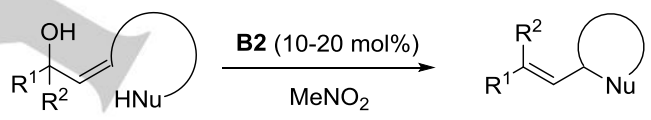

d) Rearrangement of allylic and propargylic alcohols (Chem. Sci. 2011, 47, 1305-1310 - Ref [2d])
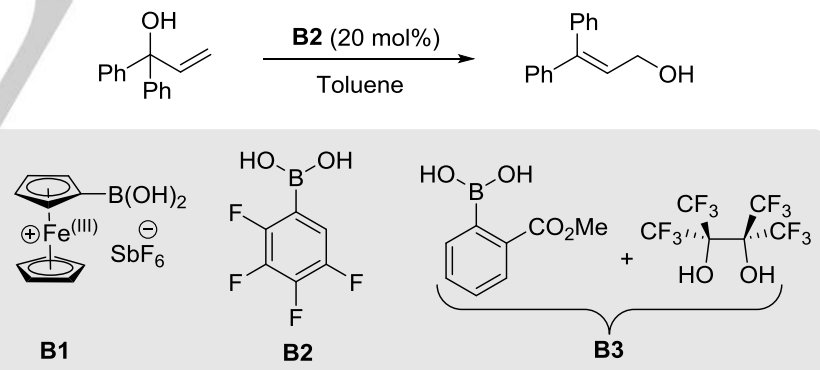

Scheme 1. Representative boronic acid catalyzed transformations of alcohols and oximes.

Pairs, ${ }^{[9]}$ we surmised that it would be unlikely that this reaction features covalent or Lewis acid catalysis. One plausible mechanism would entail catalysis by a Brønsted acid, which would be generated through the coordination of the boronic acid (in the case of B1) or the boronate ester (in the case of B3) with HFIP. ${ }^{[10]}$ Indeed, the presence of 2,6-di-tert-butylpyridine, a bulky Brønsted base commonly used to distinguish between Lewis and Brønsted acid catalysis ${ }^{[11]}$ completely shut down the reactivity in both cases, consistent with Brønsted acid catalysis (entries 1.3 and 1.6). Additionally, Brønsted acids weaker than $\mathrm{TfOH}$ were not effective catalysts (entries 1.10-1.13), leading us to suspect that very strong Brønsted acids might have been produced from the boronic acids under the reaction conditions. These observations led us to wonder whether certain previously reported boronic acid catalyzed reactions might also be the result of Brønsted acid 
Table 1. Comparison between boronic and Brønsted acids for the catalytic ringopening hydroarylation of phenylcyclopropane.

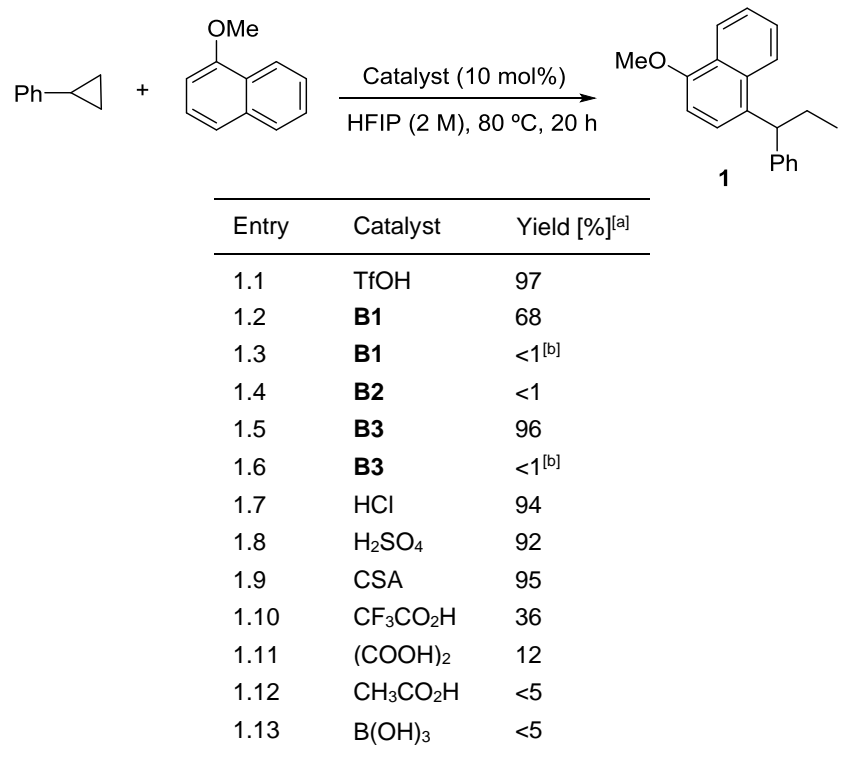

[a] Yields were determined by ${ }^{1} \mathrm{H}$ NMR using hexamethyldisiloxane as an external standard. [b] In the presence of 15 mol\% 2,6-di-tert-butylpyridine. CSA = camphorsulfonic acid.

catalysis.

Herein, we address the above issues by comparing boronic and Brønsted acid catalysts with nine formerly disclosed boronic acid catalyzed reactions spanning the four representative studies summarized in Scheme 1. We will provide a correlation between the reactivity profiles generated by the various boronic and Brønsted acids and their influence on triethylphosphine oxide (Gutmann-Beckett method). ${ }^{[12]}$ We found that in eight of the nine reactions that were probed, Brønsted acid or $\mathrm{H}$-bond catalysis, rather than a Lewis acid or covalent activation mechanism, is likely the main source of reactivity.

At the outset, to correlate the catalytic effects observed for boronic and Brønsted acids with their physicochemical properties, we elected to compare their interaction with triethylphosphine oxide (TEPO), a representative weak Lewis base, in various solvents (Figure 1). The strength of the interaction between the additive and TEPO can be inferred from the change in chemical shift in the corresponding ${ }^{31} \mathrm{P}$ NMR spectrum, compared to that obtained from a control experiment performed in the absence of additive and HFIP (i.e., $46.1 \mathrm{ppm}$ in toluene- $\mathrm{d}_{8}$ ). The control experiments confirmed our hypothesis regarding the pivotal role of the solvent. Indeed, in the presence of $\mathrm{MeNO}_{2}$ or $\mathrm{HFIP} / \mathrm{MeNO}_{2}$ (4:1), we observed substantial shifts in the ${ }^{31} \mathrm{P}$ NMR signal (53.0 and 67.1 ppm, respectively), indicating that the solvents are non-innocent in the activation of alcohols, even in the absence of Lewis or Brønsted acids. This does not come as a surprise since we and others have noticed similar reactivity trends in the past for HFIP and $\mathrm{MeNO}_{2}$. The former solvent forms aggregates that are excellent $\mathrm{H}$-bond donors, ${ }^{[7,8]}$ while the latter templates the formation of similar aggregates through interactions with molecules such as water. ${ }^{[8 a, 13]}$ In the case of the HFIP/MeNO${ }_{2}$ mixture, adding 2,6-di-tert-butylpyridine did not affect the ${ }^{31} \mathrm{P} N \mathrm{NM}$ shift, confirming that, without catalyst, no Brønsted acid is generated. Mixing catalyst system B3 with TEPO gave rise to a few new resonances, the highest frequency of which $(90.3 \mathrm{ppm})$ is
$12.1 \mathrm{ppm}$ further downfield than the signal generated due to the same experiment carried out with $\mathrm{B}\left(\mathrm{C}_{6} \mathrm{~F}_{5}\right)_{3} \cdot \mathrm{H}_{2} \mathrm{O}$ (78.2 ppm). The influence of $\mathbf{B} 3$ in $\mathrm{HFIP} / \mathrm{MeNO}_{2}$ (4:1) thus appears to be stronger than $\mathrm{B}\left(\mathrm{C}_{6} \mathrm{~F}_{5}\right)_{3} \cdot \mathrm{H}_{2} \mathrm{O}$, and comparable to that of $\mathrm{HCl}(90.7 \mathrm{ppm})$ or CSA (91.3 ppm), in close agreement with the ability of B3 to promote the opening of unactivated cyclopropanes (see Table 1). This is very different from the situation in toluene, where CSA shifts the signal of TEPO nearly 20 ppm further downfield than B3. At least one species produced from the components of B3, presumably a highly electrophilic hexafluoropinacol boronate ester, can serve to generate a strong Brønsted acid in HFIP. It should be highlighted that the diol component of $\mathbf{B} 3$ is essential here, as no shift was observed with the boronic acid alone (B3'). In line with these suggestions, it was established that a strongly Brønsted acidic species is formed from the covalent assembly of pentafluorophenylboronic acid and oxalic acid, another electronpoor bidentate species. ${ }^{[14]}$ Likewise, the shift produced by the addition of $\mathbf{B} 1$ ( $84.5 \mathrm{ppm})$ is significantly higher than that produced by $\mathrm{B}\left(\mathrm{C}_{6} \mathrm{~F}_{5}\right)_{3} \cdot \mathrm{H}_{2} \mathrm{O}$, congruent with its demonstrated reactivity (see Table 1). Although this experiment does not distinguish whether Brønsted or Lewis acids are causing the observed shifts per se, strong boron Lewis acids such as $\mathrm{B}\left(\mathrm{C}_{6} \mathrm{~F}_{5}\right)_{3}$ are well known to rapidly react with adventitious water to form hydrates that are strong Brønsted acids. ${ }^{[15]}$ In a similar way, the large magnitude of the observed shift in the ${ }^{31} \mathrm{P}$ NMR means that strong Brønsted acids are almost certainly produced by B1 and B3 in HFIP. For these reasons, the mild $\mathrm{p} K_{\mathrm{a}}$ values established for these boronic acids in DMSO or water cannot be transposed to reactions carried out in HFIP and HFIP/MeNO 2 in order to predict reactivity. Indeed, none of the shifts corresponding to the boronic acids in the absence of HFIP exceeded $61.5 \mathrm{ppm}$ (see the Supporting Information for details). Lastly, we found that boronic acid B2 (66.8 $\mathrm{ppm}$ in $\mathrm{HFIP} / \mathrm{MeNO}_{2} 4: 1$ ) induces a shift in the ${ }^{31} \mathrm{P} \mathrm{NMR}$ comparable to oxalic acid (69.5 ppm), in agreement with the lack of reactivity observed in the ring-opening transformation. Of note, in the absence of the diol component of B3, the shift is similar to that of $\mathbf{B 2}(66.9 \mathrm{ppm})$.

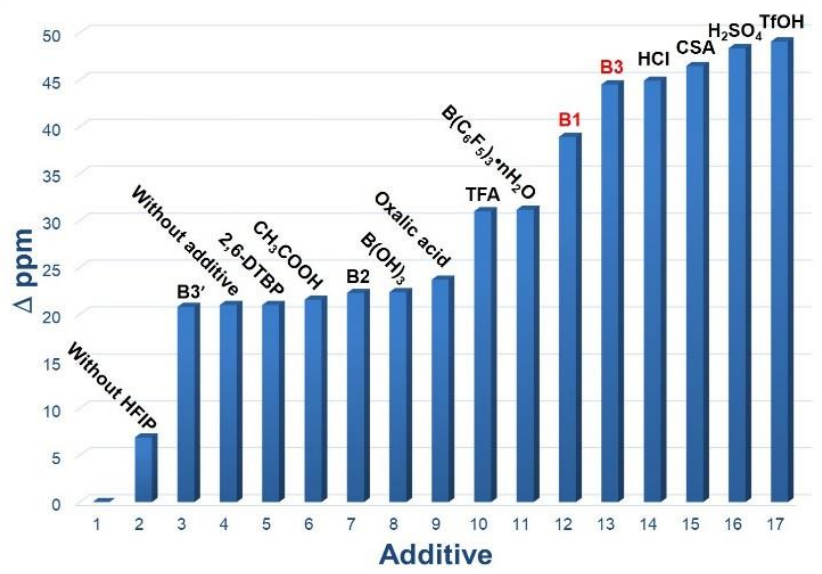

Figure 1. Gutmann-Beckett plot showing the influence of an additive (3 equiv) on TEPO (1 equiv) in HFIP/MeNO $2(4: 1)$ as expressed by the variations in chemical shift of the highest frequency signal observed in the ${ }^{31} \mathrm{P}$ NMR spectrum when compared to the reference TEPO in toluene- $\mathrm{d}_{8}$. B3' = B3 in the absence of diol.

Based on these results, the first set of transformations examined was the Friedel-Crafts reaction of primary benzylic alcohols $\mathbf{2 a - 2 c}$ catalyzed by hexafluoroantimonate salt $\mathbf{B 1}$ in $\mathrm{HFIP} / \mathrm{MeNO}_{2}$ 
(4:1). ${ }^{[2 g]}$ The three substrates reacted as previously described (Table 2, entry 2.1) but not in the presence of 2,6-di-tertbutylpyridine (entry 2.2). ${ }^{[16]}$ Replacing the cationic boronic acid by Brønsted acids spanning a wide $p K_{\mathrm{a}}$ range revealed that, in all cases, the boronic acid may be substituted with a Brønsted acid with similar results, although the strength of the required acid varies with the nature of the electronic substituents on the benzylic alcohol. The conjugate acid of the boronic acid catalyst, $\mathrm{HSbF}_{6}$, catalyzed the reaction of all three substrates (entry 2.3), albeit in lower yields. In the case of benzylic alcohols $\mathbf{2} \mathbf{a}$ and $\mathbf{2} \mathbf{b}$, the weak Brønsted acid oxalic acid was surprisingly able to promote the reaction under otherwise identical conditions (entries 2.9-2.11). Electronically deactivated alcohol $\mathbf{2 c}$ needed a stronger Brønsted acid but its transformation could still be effectively catalyzed by $\mathrm{H}_{2} \mathrm{SO}_{4}$ (entry 2.6). Previously, the possibility of Brønsted acid catalysis was ruled out on the basis of: 1) the lack of reactivity of $\mathbf{2} \mathbf{b}$ with $\mathrm{CF}_{3} \mathrm{CO}_{2} \mathrm{H}$ and 2 ) the fact that a different boronic acid (B2), which has a comparable $\mathrm{p} K_{\mathrm{a}}$ in $\mathrm{H}_{2} \mathrm{O}$ and DMSO to the catalyst used $(\mathbf{B} 1),{ }^{[2 h, 17]}$ does not facilitate the reaction in $\mathrm{HFIP} / \mathrm{MeNO}_{2}$. However, as the data provided in Figure 1 emphasized, $\mathbf{B} 2$ and $\mathrm{CF}_{3} \mathrm{CO}_{2} \mathrm{H}$ do not produce a suitably strong Brønsted acid in $\mathrm{HFIP} / \mathrm{MeNO}_{2}$ and thus are not suitable points of reference. The reduced reactivity of $\mathbf{B} \mathbf{3}$ compared to $\mathbf{B} \mathbf{1}$, can be explained by the sequestration of the diol component of $\mathbf{B} 3$ by $\mathrm{H}$ bonding with an excess of benzylic alcohol substrate, ${ }^{[18]}$ leaving behind boronic acid B3' as a much weaker catalyst as expected from Figure 1.

transformations catalyzed by B3 were efficient in each instance (Table 3, entry 3.3) but not in the presence of 2,6-di-tertbutylpyridine (entry 3.4). In the case of $\mathbf{4 a}$, none of the Brønsted acids tested promoted the rearrangement. In the catalytic experiments with $\mathbf{B 3}$, the reaction kinetics for $\mathbf{4 a}$ did display an induction period consistent with a slow catalyst formation and the previously proposed covalent mechanism. However, since all prior optimization and mechanistic studies were conducted on $\mathbf{4 a}$, this might have led the authors to conclusions about the mechanism which do not hold for other substrates. For substrates $\mathbf{4 b} \mathbf{b} \mathbf{4 d}$, a screen of Brønsted acids revealed several to be capable of promoting the reaction with either a similar efficiency or even more effectively than the B3 catalyst system (entries 3.5-3.9). CSA proved to be particularly effective in the case of substrates $4 \mathbf{b}$ and $4 \mathbf{c}$, while $\mathrm{CF}_{3} \mathrm{CO}_{2} \mathrm{H}$ was able to promote the reaction with 4d (entries 3.8-3.9). Indeed, the kinetic profile of the reaction of oxime $\mathbf{4 b}$ catalyzed by $\mathbf{B} 3$ proved to be nearly identical to that catalyzed by CSA, with no observation of an induction period expected for a mechanism involving slow formation of a catalytically active acyl oxime species (see Supporting Information for details). These experiments thus support Brønsted acid catalysis, rather than covalent catalysis, being the dominant mechanism for substrates $\mathbf{4 b}-\mathbf{4 d}$. Covalent activation and Brønsted acid catalysis therefore appear to be competitive catalytic mechanisms in the Beckmann rearrangement, with three of the four representative substrates dominated by Brønsted acid catalysis.

Table 3. Comparison between boronic acids and Brønsted acids for the catalytic Beckmann rearrangement. ${ }^{[a]}$ dehydrative Friedel-Crafts reactions of benzylic alcohols. ${ }^{[a]}$

$$
\begin{aligned}
& \overbrace{4 a-4 d}^{N_{R_{2}}^{-O H}} \\
& \underset{\mathrm{HFIP} / \mathrm{MeNO}_{2}(4: 1)}{\stackrel{\begin{array}{c}
\text { catalyst } \\
\text { perfluoropinacol }
\end{array}}{\mathrm{H}}}
\end{aligned}
$$

4a: $\mathrm{R}_{1}=\mathrm{C}_{6} \mathrm{H}_{5}, \mathrm{R}_{2}=\mathrm{Me}$

4b: $\mathrm{R}_{1}=4-\mathrm{OH}-\left(\mathrm{C}_{6} \mathrm{H}_{4}\right), \mathrm{R}_{2}=\mathrm{Me}$

\begin{tabular}{|c|c|c|c|c|c|}
\hline Entry & Catalyst & $\begin{array}{l}\text { Yield 5a } \\
{[\%]^{[b]}}\end{array}$ & $\begin{array}{l}\text { Yield 5b } \\
{[\%]^{[c]}}\end{array}$ & $\begin{array}{l}\text { Yield 5c } \\
{[\%]^{[c]}}\end{array}$ & $\begin{array}{l}\text { Yield 5d } \\
{[\%]^{[b]}}\end{array}$ \\
\hline 3.1 & B1 & $<1$ & 20 & $<10$ & $<1$ \\
\hline 3.2 & B2 & $<1$ & $<1$ & $<1$ & $<1$ \\
\hline 3.3 & B3 & 98 & 94 & 85 & 45 \\
\hline 3.4 & B3 & $<1^{[d]}$ & $<1^{[\mathrm{e}]}$ & $<1^{[\mathrm{e}]}$ & $<1^{[d]}$ \\
\hline 3.5 & $\mathrm{TfOH}$ & $<1$ & 40 & 96 & $<1$ \\
\hline 3.6 & $\mathrm{HCl}$ & $<1$ & 16 & 26 & $<1$ \\
\hline 3.7 & $\mathrm{H}_{2} \mathrm{SO}_{4}$ & $<1$ & $<1$ & $<1$ & $<1$ \\
\hline 3.8 & CSA & $<1$ & 90 & 86 & 20 \\
\hline 3.9 & $\mathrm{CF}_{3} \mathrm{CO}_{2} \mathrm{H}$ & $<1$ & 36 & 21 & 78 \\
\hline 3.10 & $(\mathrm{COOH})_{2}$ & $<1$ & $<1$ & $<1$ & $<1$ \\
\hline 3.11 & $\mathrm{CH}_{3} \mathrm{CO}_{2} \mathrm{H}$ & $<1$ & $<1$ & $<1$ & $<1$ \\
\hline 3.12 & $\mathrm{~B}(\mathrm{OH})_{3}$ & $<1$ & $<1$ & $<1$ & $<1$ \\
\hline
\end{tabular}

4c: $\mathrm{R}_{1}=\mathrm{Ph}, \mathrm{R}_{2}=\mathrm{Ph}$

4d: $\mathrm{R}_{1}=\mathrm{R}_{2}=-\left(\mathrm{CH}_{2}\right)_{5}$

[a] Yields were determined by ${ }^{1} \mathrm{H}$ NMR using hexamethyldisiloxane as an external standard. [b] 30 mol\% catalyst and perfluoropinacol, $80{ }^{\circ} \mathrm{C}, 24$ h. [c] 5 mol\% catalyst and perfluoropinacol, $25{ }^{\circ} \mathrm{C}, 24 \mathrm{~h}$. [b] 30 mol\% catalyst and perfluoropinacol, $80{ }^{\circ} \mathrm{C}, 24 \mathrm{~h}$. [d] With $45 \mathrm{~mol} \%$ 2,6-di-tert-butylpyridine. [e] With 7.5 mol\% 2,6-di-tert-butylpyridine.

The third reaction that we analyzed was the carbocyclization of allylic alcohols, reported to be catalyzed by boronic acid $\mathbf{B 2}$ in $\mathrm{MeNO}_{2}{ }^{[2 f]}$ The transformation occurred as described (Table 4, 
entry 4.2), but was inefficient in the presence of 2,6-di-tertbutylpyridine (entry 4.3). Likewise, B1 and B3 have a relatively similar efficacy (entries 4.1 and 4.4). In contrast, a Brønsted acid as weak as oxalic acid enabled the reaction under otherwise identical conditions (entries 4.11). Both oxalic acid and boronic acids are known to act as dual $\mathrm{H}$-bond donors, ${ }^{[19]}$ and likely act as $\mathrm{H}$-bond catalysts here. The possibility of $\mathrm{H}$-bond activation may have been previously overlooked, since in the original disclosure, control experiments designed to compare B2 to Brønsted acids were performed with $p$-TsOH only (entry 4.8).

Table 4. Comparison between boronic acids and Brønsted acids for the catalytic carbocyclization of allylic alcohols.

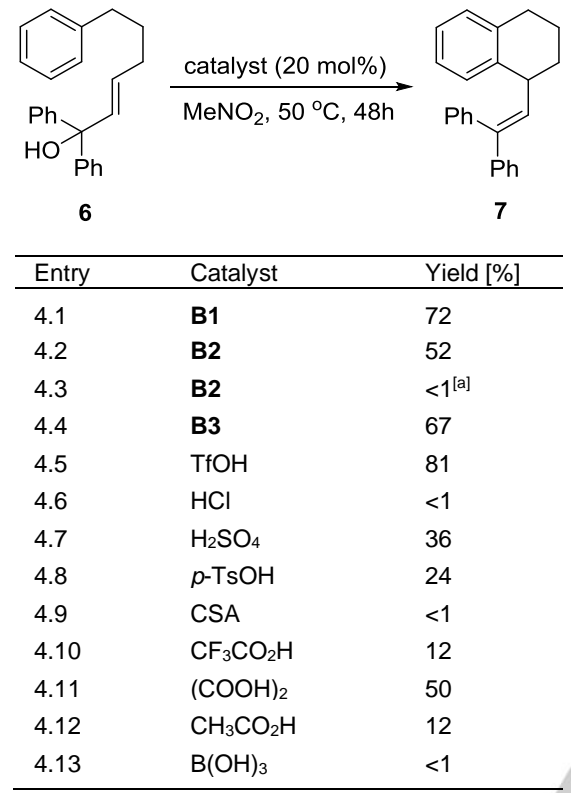

[a] Yields were determined by ${ }^{1} \mathrm{H}$ NMR using hexamethyldisiloxane as an external standard. [b] In the presence of 15 mol\% 2,6-di-tert-butylpyridine.

The last process explored was the 1,3-allylic transposition of 1,1diphenyl allyl alcohol, also reported to be catalyzed by $\mathbf{B 2}$ (Table 5). ${ }^{[2 d]}$ This reaction proved to be more challenging to rationalize as we faced a major hurdle to reproduce the published results. Using either commercially available or freshly prepared and recrystallized catalyst B2, yields never exceeded $20 \%$. We suspect that the reported success of this transformation might result from the presence of an impurity in the way that $\mathbf{B 2}$ was synthesized (a borinic acid or traces of another acid, for instance). Even a trace impurity might not be negligible given the catalyst loading of $20 \mathrm{~mol} \%$. In turn, stronger Brønsted acids enabled the reaction to a limited extent (entries 5.5-5.7), but CSA was highly effective, delivering the product in $85 \%$ yield (entry 5.8 ). This result is similar to those reported in the literature, which again strongly suggest Brønsted acid catalysis.

Table 5. Comparison between boronic acids and Brønsted acids for the catalytic 1,3-allylic transposition of allylic alcohols. ${ }^{[a]}$

\begin{tabular}{|c|c|c|}
\hline 8 & & 9 \\
\hline Entry & Catalyst & Yield [\%] \\
\hline 5.1 & B1 & 46 \\
\hline 5.2 & B2 & $20(80)^{[b]}$ \\
\hline 5.3 & B2 & $<1^{[c]}$ \\
\hline
\end{tabular}

\begin{tabular}{lll}
5.4 & B3 & $<1$ \\
5.5 & $\mathrm{TfOH}$ & 6 \\
5.6 & $\mathrm{HCl}$ & 16 \\
5.7 & $\mathrm{H}_{2} \mathrm{SO}_{4}$ & 44 \\
5.8 & $\mathrm{CSA}$ & 85 \\
5.9 & $\mathrm{CF}_{3} \mathrm{CO}_{2} \mathrm{H}$ & 18 \\
5.10 & $(\mathrm{COOH})_{2}$ & 11 \\
5.11 & $\mathrm{CH}_{3} \mathrm{CO}_{2} \mathrm{H}$ & $<1$ \\
5.12 & $\mathrm{~B}(\mathrm{OH})_{3}$ & $<1$ \\
\hline
\end{tabular}

[a] Yields were determined by ${ }^{-1} \mathrm{H}$ NMR using hexamethyldisiloxane as an external standard. [b] Yield reported in reference 2d. [c] In the presence of 15 mol\% 2,6-di-tert-butylpyridine.

To summarize, this study sheds light on the activation mode of boronic acid catalysis of alcohols and oximes, showing that Brønsted acid and $\mathrm{H}$-bond catalysis, rather than Lewis acid or covalent activation, are likely responsible for the observed reactivity in nearly all the representative examples studied. Specifically, catalysts B1 and B3 produce strong Brønsted acids in the presence of HFIP, and catalyst B2 likely acts as a $\mathrm{H}$-bond catalyst in $\mathrm{MeNO}_{2}$. We have concluded the above on the basis of the following key findings: 1) Boronic acids B1 and B3 are able to rupture unactivated cyclopropanes in HFIP. 2) The hindered Brønsted base 2,6-di-tert-butylpyridine entirely inhibits reactivity of the boronic acids in the reactions investigated. 3) Boronic acid catalyzed reactions of alcohols and oximes can be promoted by Brønsted acids or $\mathrm{H}$-bond catalysts. 4) Brønsted acids that facilitate those transformations exert a deshielding influence on TEPO comparable to the boronic acids that promote the same transformations. 5) For three of the four representative oximes studied, the data collected are inconsistent with a covalent mechanism. Moving forward, these insights should be useful for the rational design of second-generation catalysts for dehydrative nucleophilic substitution or for oxime rearrangements, whether or not they are based on boron. Finally, this work cautions that, before novel catalytic mechanisms are proposed, a wide range of control experiments are necessary to rule out a catalytic role for Brønsted acid and $\mathrm{H}$-bond donors, taking into consideration the important numerous roles played by the solvent.

\section{Acknowledgements}

J.M. thanks the European Research Council (ERC) (grant agreement $n^{\circ}$ 639170), ANR LabEx "Chemistry of Complex Systems" (ANR-10-LABX-0026 CSC) and CNRS. S. Z. thanks the China Scholarship Council for a fellowship. We thank Prof. D. G. Hall for discussion and comments.

\section{Notes}

The authors declare no competing financial interest.

\section{Acknowledgements}

J.M. thanks the European Research Council (ERC) (grant agreement $n^{\circ}$ 639170), ANR LabEx "Chemistry of Complex Systems" (ANR-10-LABX-0026 CSC) and CNRS. S. Z. thanks the China Scholarship Council for a fellowship. We thank Prof. D. G. Hall for discussion and comments. 
Keywords: boronic acid $\bullet$ hexafluoroisopropanol $•$ Bønsted acid - Lewis acid $\bullet$ dual H-bond

[1] For reviews on boronic acid catalysis, see: a) E. Dimitrijević, M. S. Taylor ACS Catal. 2013, 3, 945-962; b) H. C. Zhang, D. G. Hall, Aldrichim. Acta. 2014, 47, 41-51; c) D. G. Hall, Chem. Soc. Rev. 2019, 48, 3475-3496.

[2] For catalytic activation of alcohols by boronic acids, see: a) J. A McCubbin, O. V. Krokhin, Tetrahedron Lett. 2010, 51, 2447-2449; b) J. A. McCubbin, H. Hosseini, O. V. Krokhin, J. Org. Chem. 2010, 75, 959 962; c) J. A. McCubbin, C. Nassar, O. V. Krokhin, Synthesis 2011, 19 3152-3160; d) H. Zheng, M. Lejkowski, D. G. Hall, Chem. Sci. 2011, 2 1305-1310; e) J. A. McCubbin, C. Nassar, O. V. Krokhin, Synthesis 2011, 3152-3160; f) H. C. Zheng, S. Ghanbari, S. Nakamura, D. G. Hall, Angew. Chem. Int. Ed. 2012, 51, 6187-6190; g) X. B. Mo, J. Yakiwchuk, J. Dansereau, J. A. McCubbin, D. G. Hall, J. Am. Chem. Soc. 2015, 137 9694-9703; h) C. L. Ricardo, X. B. Mo, J. A. McCubbin, D. G. Hall, Chem. Eur. J. 2015, 21, 4218-4223; i) W.-B. Tang, K.-S. Cao, S.-S. Meng, W.H. Zheng, Synthesis 2017, 49, 3670-3675; j) H. T. Ang, J. P. G. Rygus, D. G. Hall, Org. Biomol. Chem. 2019, 17, 6007-6014.

[3] For catalytic activation of oximes by boronic acids, see: a) S Chandrasekhar, K. Gopalaiah, Tetrahedron Lett. 2002, 43, 2455-2457 b) X. B. Mo, T. D. R. Morgan, H. T. Ang, D. G. Hall, J. Am. Chem. Soc 2018, 140, 5264-5271

[4] For catalytic activation of carboxylic acids by boronic acids, see: a) R. M Al-Zoubi, O. Marion, D. G. Hall, Angew. Chem. Int. Ed. 2008, 47, 2876 2879; b) A. Sakakura, T. Ohkubo, R. Yamashita, M. Akakura, K. Ishihara Org. Lett. 2011, 13, 892-895; c) N. Gernigon, R. M. Al-Zoubi, D. G. Hall, J. Org. Chem. 2012, 77, 8386-8400; d) C. Wang, H. Z. Yu, Y. Fu, Q. X. Guo, Org. Biomol. Chem. 2013, 11, 2140-2146; e) N. Gernigon, H. C. Zheng, D. G. Hall, Tetrahedron Lett. 2013, 54, 4475-4478; f) K. Ishihara Y. H. Lu, Chem. Sci. 2016, 7, 1276-1280; g) K. Wang, Y. H. Lu, K. Ishihara, Chem. Commun. 2018, 54, 5410-5413; h) S. Arkhipenko, M. T. Sabatini, A. S. Batsanov, V. Karaluka, T. D. Sheppard, H. S. Rzepa, A Whiting, Chem. Sci. 2018, 9, 1058-1072.

[5] a) J. Liu, H. Yao, C. Wang, ACS Catal. 2018, 8, 9376-9381; b) H. Yao, J. Liu, C. Wang, Org. Biomol. Chem. 2019, 17, 1901-1905.

[6] For recent reviews on HFIP, see: a) T. Sugiishi, M. Matsugi, H. Hamamoto, H. Amii, RSC Adv. 2015, 5, 17269-17282; b) J. WencelDelord, F. Colobert, Org. Chem. Front. 2016, 3, 394-400; c) I. Colomer A. E. R. Chamberlain, M. B. Haughey, T. J. Donohoe, Nat. Rev. Chem. 2017, 1, 0088; d) S. K. Sinha, T. Bhattacharya, D. Maiti, React. Chem. Engl. 2019, 4, 244-253.

[7] For recent examples of enhancement of reactivity via the use of HFIP, see: a) A. Berkessel, J. A. Adrio, D. Hüttenhain, J. M. Neudörfl, J. Am. Chem. Soc. 2006, 128, 8421-8426; b) A. Berkessel, J. A. Adrio, J. Am. Chem. Soc. 2006, 128, 13412-13420; c) H. F. Motiwala, C. Fehl, S.-W. Li, E. Hirt, P. Porubsky, J. Aubé, J. Am. Chem. Soc. 2013, 135, 90009009; d) R. H. Vekariya, J. Aubé, Org. Lett. 2016, 18, 3534-3537; e) X Zeng, S. Liu, B. Xu, Org. Lett. 2016, 18, 4770-4773; f) I. Colomer, R. C Barcelos, K. E. Christensen, T. J. Donohoe, Org. Lett. 2016, 18, 58805883; g) T. Kamitanaka, K. Morimoto, K. Tsuboshima, D. Koseki, H. Takamuro, T. Dohi, Y. Kita, Angew. Chem. Int. Ed. 2016, 55, 15535 15538; h) I. Colomer, C. Batchelor-McAuley, B. Odell, T. J. Donohoe, R G. Compton, J. Am. Chem. Soc. 2016, 138, 8855-8861; i) D. Lebœuf, L. Marin, B. Michelet, A. Perez-Luna, R. Guillot, E. Schulz, V. Gandon Chem. Eur. J. 2016, 22, 16165-16171; j) V. D. Vuković, E. Richmond, E. Wolf, J. Moran, Angew. Chem. Int. Ed. 2017, 56, 3085-3089; k) C. Qi, F. Hasenmaile, V. Gandon, D. Lebœuf, ACS Catal. 2018, 8, 1734-1739; I) Z. Tao, K. A. Robb, K. Zhao, S. E. Denmark, J. Am. Chem. Soc. 2018 140, 3569-3573; m) E. Richmond, J. Yi, V. D. Vuković, F. Sajadi, C. N. Rowley, J. Moran, Chem. Sci. 2018, 9, 6411; n) C. Qi, V. Gandon, D. Lebœuf, Angew. Chem. Int. Ed. 2018, 57, 14245-14249; o) Y. Zhu, I. Colomer, A. L. Thompson, T. J. Donohoe, J. Am. Chem. Soc. 2019, 141 6489-6493.

[8] a) M. Dryzhakov, M. Hellal, E. Wolf, F. C. Falk, J. Moran, J. Am. Chem. Soc. 2015, 137, 9555-9558; b) M. Dryzhakov, J. Moran, ACS Catal. 2016 $6,3670-3673$

[9] J. G. M. Morton, M. A. Dureen, D. W. Stephan, Chem. Commun. 2010, 46, 8947-8949.

[10] For selected papers where transition metal-promoted reactions were later found to be Brønsted acid catalyzed processes, see: a) B. Schlummer, J. F. Hartwig, Org. Lett. 2002, 4, 1471-1474; b) T. C Wabnitz, J.-Q. Yu, J. B. Spencer, Chem. Eur. J. 2004, 10, 484-493; c) D. C. Rosenfeld, S. Shekhar, A. Takemiya, M. Utsunomiya, J. F. Hartwig Org. Lett. 2006, 8, 4179-4182; d) P. N. Liu, Z. Y. Zhou, C. P. Lau, Chem. Eur. J. 2007, 13, 8610-8619; e) T. Jin, F. Yang, C. Liu, Y. Yamamoto Chem. Commun. 2009, 3533-3535; f) T. T. Dang, F. Boeck, L. Hintermann, J. Org. Chem. 2011, 76, 9353-9361; g) H. J. Jin, J. H. Kim, E. J. Kang, Synthesis 2017, 49, 3137-3144; h) E. T. Sletten, Y.-J. Tu, H B. Schlegel, H. M. Nguyen, ACS Catal. 2019, 9, 2110-2123.

[11] The bulky pyridine 2,6-di-tert-butylpyridine (DTBP) is commonly used to distinguish between boron or other Lewis acids and Brønsted acids because it does not complex most Lewis acids, including boron: a) H. C Brown, B. Kanner, J. Am. Chem. Soc. 1966, 88, 986-992; b) P. G.
Gassman, D. A. Singleton, J. Am. Chem. Soc. 1984, 106, 7993-7994; c) C. Bergquist, B. M. Bridgewater, C. J. Harlan, J. R. Norton, R. A. Friesner, G. Parkin, J. Am. Chem. Soc. 2000, 122, 10581-10590; d) M. Yasuda, T. Somyo, A. Baba, Angew. Chem. Int. Ed. 2006, 45, 793-796; e) M. Vayer R. Guillot, C. Bour, V. Gandon, Chem Eur. J. 2017, 23, 13901-13905.

[12] a) V. Gutmann, Coordination Chemistry Reviews 1976, 18, 225-255; b) H. Großekappenberg, M. Reißmann, M. Schmidtmann, T. Müller, Organometallics 2015, 34, 4952-4958; c) M. A. Beckett, D. S. Brassington, S. J. Coles, M. B. Hursthouse, Inorg. Chem. Commun. 2000, 3, 530-533; d) G. C. Welch, L. Cabrera, P. A. Chase, E. Hollink, J. D. Masuda, P. R. Wei, D. W. Stephan, Dalton Trans. 2007, 3407-3414; e) J. Alarcón-Espósito, R. Contreras, R. A. Tapia, P. R. Campodónico, Chem. Eur. J. 2016, 22, 13347-13351.

[13] J. J. Montalvo-Acosta, M. Dryzhakov, E. Richmond, M. Cecchini, J. Moran, under revisions.

[14] a) S. Estopiña-Durán, L. J. Donnelly, E. B. Lclean, B. M. Hockin, A. M. Z Slawin, J. E. Taylor, Chem. Eur. J. 2019, 25, 3950-3956; b) E. Wolf, E. Richmond, J. Moran, Chem. Sci. 2015, 6, 2501-2505.

[15] T. Beringhelli, D. Maggioni, G. D'Alfonso, Organometallics 2001, 20 , 4927-4938.

[16] The possibility that the inhibiting effect of DTBP might be due to poisoning of the boronic acid by alkoxide generated from deprotonation of HFIP seems unlikely due to the following experiment: we found the boronic acid catalyzed reaction also occurred in the absence of DTBP in the aprotic solvent DCE under slightly higher temperatures. It is also inhibited by DTBP under these conditions, where no alkoxides are present (see the Supporting Information for more information).

[17] A. N. J. Moore, D. D. M. Wayner, Can. J. Chem. 1999, 77, 681-686.

[18] A. Shokri, X.-B. Wang, S. R. Kass, J. Am. Chem. Soc. 2013, 135, 9525 9530.

[19] a) K. M. Diemoz, A. K Franz, J. Org. Chem. 2019, 84, 1126-1138; b) G. Lv, X. Sun, C. Zhang, M. Lei, Atmos. Chem. Phys. 2019, 19, 2833-2844. 


\section{Entry for the Table of Contents}

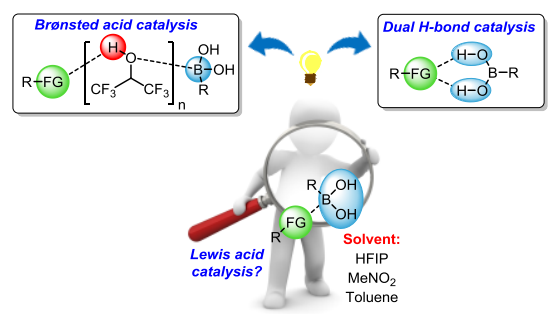

To B or not to B: We shed new light on the mechanism of boronic acid catalysis for reactions of alcohols or oximes, which were thought to involve the boron atom acting as a Lewis acid or to feature the transient formation of covalent bonds to boron. The present study suggests they simply act as H-bond donors or Brønsted acids.

Institute and/or researcher Twitter usernames: @djpleboeuf and @MoranLabUdS 